\title{
Mycobacterium tuberculosis from chronic murine infections that grows in liquid but not on solid medium Jasvir Dhillon ${ }^{1}$, Douglas B Lowrie ${ }^{2}$ and Denis A Mitchison*1
}

Address: ${ }^{1}$ Department of Cellular and Molecular Medicine, St George's Hospital Medical School, London SW17 ORE, UK and ${ }^{2}$ National Institute For Medical Research, Mill Hill, London NW7 1AA, UK

Email: Jasvir Dhillon - jdhillon@sghms.ac.uk; Douglas B Lowrie - dlowrie@nimr.mrc.ac.uk; Denis A Mitchison* - dmitchis@sghms.ac.uk

* Corresponding author

Published: 17 November 2004

BMC Infectious Diseases 2004, 4:5 I doi:10.1 I86/I47|-2334-4-5I

This article is available from: http://www.biomedcentral.com/I47I-2334/4/5 I

(C) 2004 Dhillon et al; licensee BioMed Central Ltd.

This is an Open Access article distributed under the terms of the Creative Commons Attribution License (http://creativecommons.org/licenses/by/2.0), which permits unrestricted use, distribution, and reproduction in any medium, provided the original work is properly cited.
Received: 10 March 2004

Accepted: 17 November 2004

\begin{abstract}
Background: Old, stationary cultures of Mycobacterium tuberculosis contain a majority of bacteria that can grow in broth cultures but cannot grow on solid medium plates. These may be in a nonreplicating, dormant growth phase. We hypothesised that a similar population might be present in chronic, murine tuberculosis.

Methods: Estimates of the numbers of viable M. tuberculosis, strain $\mathrm{H} 37 \mathrm{Rv}$, in the spleens and lungs of mice in a 7-day acute infection and in a 10 -month chronic infection were made by conventional plate counts and, as broth counts, by noting presence or absence of growth in serial replicate dilutions in liquid medium.

Results: Plate and broth counts in 6 mice gave similar mean values in the acute infection, 7 days after infection. However, the broth counts were much higher in 36 mice with a chronic infection at 10 months. Broth counts averaged $5.290 \log _{10}$ cfu /organ from spleens and $5.523 \log _{10}$ cfu/organ from lungs, while plate counts were $3.858 \log _{10}$ cfu/organ from spleens and $3.662 \log _{10}$ cfu/organ from lungs, indicating that the total bacterial population contained only $3.7 \%$ bacilli in spleens and $1.4 \%$ bacilli in lungs, capable of growth on plates.
\end{abstract}

Conclusion: The proportion growing on plates might be a measure of the "dormancy" of the bacilli equally applicable to cultural and animal models.

\section{Background}

The organisms in a log phase, actively multiplying culture of Mycobacterium tuberculosis all grow well on plates and are estimated as colony forming units (cfu). However, cultures that have been grown undisturbed in the depths of liquid medium for 100 days contain a majority population which grows in liquid medium but is not able to form colonies on solid medium $[1,2]$. Since the bacilli in such cultures are hardly multiplying and have an uptake of [ $\left.{ }^{3} \mathrm{H}\right]$ uridine of only $15 \%$ of log phase cultures [1], they may be considered as dormant. A smaller population, that could grow on plates as well as in broth, possibly the survivors of the log phase bacilli, has also been demonstrated in these cultures. At the end of a 10-month mouse experiment on vaccines, we questioned whether the same two populations would be found, particularly in view of the evidence that there are similarities in gene expression patterns following adaptation to micro-aerophilic conditions in stationary cultures and exposure to NO in macrophages [3]. We therefore estimated populations present in the 
chronic infections in the organs of the 10-month mice both by conventional plate counts and by counts of the probable number of viable organisms obtained from serial dilutions in liquid medium. Similar counts were also set up, as a control, in a short-term acute infection in mice.

\section{Methods \\ Culture media and bacteria}

The media used were 7H9 liquid medium with $10 \%$ albumin, dextrose, catalase supplement and $0.05 \%$ Tween 80 , and $7 \mathrm{H} 11$ agar medium with $10 \%$ oleic acid, albumin, dextrose, catalase supplement (Becton Dickinson, Oxford, UK). They were made selective by the addition of $100 \mu \mathrm{g}$ carbenicillin, $200 \mathrm{U}$ polymyxin $\mathrm{B}, 20 \mu \mathrm{g}$ trimethoprim and $10 \mu \mathrm{g}$ amphotericin B per ml (Mast, Bootle, UK) [4]. The two experiments both used 6-week, female Balbc mice, which were infected, with a mouse passaged H37Rv strain of $M$. tuberculosis suspended in $0.1 \%$ gelatin. The spleens and lungs were obtained at sterile autopsy and were homogenised as described elsewhere [5] in $5 \mathrm{ml}$ water. From this suspension $100 \mu \mathrm{l}$ amountsfrom the neat suspension and from serial 10-fold dilutions in $1 \mathrm{ml}$, were inoculated onto duplicate thirds of selective 7H11 medium plates. The number of colonies was counted after 3-4 weeks incubation at $37^{\circ} \mathrm{C}$ to give the plate count. A negative plate therefore had $<25 \mathrm{cfu} /$ organ. For the broth counts, serial 10 -fold dilutions of the organ homogenate were made, in triplicate, in $1 \mathrm{ml}$ amounts to $9 \mathrm{ml}$ amounts of selective $7 \mathrm{H} 9$ broth with $0.05 \%$ Tween 80 in plastic 28 $\mathrm{ml}$ screw-capped bottle. In the acute infection, 10 serial dilution were set up, so as to obtain 30 tubes in all, while in the chronic infection 6 serial dilutions were set up yielding 18 tubes in all. These were incubated at $37^{\circ} \mathrm{C}$ and examined at 3 and 6 weeks and finally at 9 weeks for the characteristic growth of $M$. tuberculosis, namely a clear supernatant in undisturbed cultures with an upwards swirl of white growth on shaking,. Probable numbers of bacilli (pnb) per organ were obtained from a table of densities of organisms estimated by the dilution method [6]. Samples of the positive growth from 18 broth cultures were plated out on 7H11 medium.

\section{Acute infection experiment}

Each of 6 mice was infected by the intravenous route with $200 \mu \mathrm{l}$ of a suspension of a containing $2.6 \times 10^{6} \mathrm{cfu}$ of the H37Rv strain. Plate and broth counts were carried out 7 days later.

\section{Chronic infection experiment}

Each of 88 mice was infected by the intra-peritoneal route with $200 \mu \mathrm{l}$ of a suspension containing $3.1 \times 10^{3} \mathrm{cfu}$ of the $\mathrm{H} 37 \mathrm{Rv}$ strain. Mice in our experiments are usually housed in an isolator, connected by a tunnel port to a Class 1 safety cabinet through which air from the environment is sucked. The intra-peritoneal route was chosen so that mice could be kept throughout the experiment in the isolator to prevent cross infection with mouse pathogens during exposure to the outside air in the Class 1 cabinet. One day after infection, samples of 6 mice yielded scanty or no colonies in plate counts of spleens and lungs. After a further 4 weeks these organ counts in 6 mice had risen to $2.24 \times 10^{4}$ in spleens and $1.15 \times 10^{4}$ in lungs. The mice were then divided into 6 experimental groups, 4 of which were vaccinated with various DNA vaccines over a 4 -week period and 2 were unvaccinated controls. At 12 weeks after infection only 9 of 36 lungs and 18 of 36 spleens yielded positive growth on plates. At 10 months after infection, the 36 remaining mice were sacrificed, and plate and broth counts were set up on all, using dilutions estimated from a sample of 4 mice sacrificed 3 weeks earlier.

\section{Statistics}

The results of the plate and broth counts were examined by 2-way analysis of variance using the Stata package, release 8 (Stata Corp., College Station, TX)

Table I: Example of a broth count from a chronic infection mouse

\begin{tabular}{cccc}
\hline & \multicolumn{3}{c}{ Tubes } \\
Dilution & 1 & 2 & 3 \\
\hline $10^{-5}$ & 0 & 0 & 0 \\
$10^{-4}$ & 0 & 0 & 0 \\
$10^{-3}$ & 0 & + & 0 \\
$10^{-2}$ & + & + & + \\
$10^{-1}$ & + & + & + \\
$10^{0}$ & + & + & + \\
\hline
\end{tabular}

The mean fertile level $(X)=$ no. of fertile cultures $(10) /$ no. of cultures at each level (3). $K=0.760$ from Table [6]. $\log p n b=X-K+\log 5($ organ in $5 \mathrm{ml})=3.272$

\section{Results}

As the experimental vaccines appeared to have only small effects, which will be reported elsewhere, in the chronic infection model, the results in all 36 mice at 10 months are considered together. A typical broth count is shown diagrammatically in Table 1 . Note that there were never any sporadic positive tubes in the no growth zones (inoculated in the example with $10^{-4}$ or $10^{-5}$ dilutions) of any set of broth cultures. The results in the 6 mice in the acute infection experiment and in 27 of the 36 mice in the chronic infection experiment that had assessable numbers of bacilli estimated as cfu by the plate method and as pnb by the broth method are set out in Table 2. In the analysis of variance of the acute infection counts, neither the variation between individual mice nor the difference between 
Table 2: Plate and broth counts of $M$. tuberculosis in spleen and lungs of mice with acute and chronic infections

\begin{tabular}{|c|c|c|c|c|c|c|}
\hline \multirow{2}{*}{$\begin{array}{c}\text { Infection } \\
\text { Acute (6 mice) }\end{array}$} & \multirow{2}{*}{$\begin{array}{c}\text { Mouse organ } \\
\text { Spleen }\end{array}$} & \multirow{2}{*}{$\begin{array}{c}\text { Type of count* } \\
\text { Plate }\end{array}$} & \multirow{2}{*}{$\begin{array}{c}\text { Mean count } \\
7.070\end{array}$} & \multirow{2}{*}{$\begin{array}{c}\text { SD } \\
0.214\end{array}$} & \multicolumn{2}{|c|}{$95 \%$ confidence limits } \\
\hline & & & & & 6.845 & 7.295 \\
\hline & & Broth & 6.663 & 0.771 & 5.854 & 7.472 \\
\hline & Lungs & Plate & 6.703 & 0.095 & 6.603 & 6.803 \\
\hline & & Broth & 6.609 & 0.421 & 6.167 & 7.050 \\
\hline \multirow[t]{4}{*}{ Chronic (27 mice) } & Spleen & Plate & 3.858 & 0.882 & 3.509 & 4.207 \\
\hline & & Broth & 5.290 & 0.820 & 4.966 & 5.614 \\
\hline & Lungs & Plate & 3.662 & 1.462 & 3.084 & 4.240 \\
\hline & & Broth & 5.523 & 0.939 & 5.152 & 5.894 \\
\hline
\end{tabular}

* Plate counts are $\log _{10}$ cfu/organ. Broth counts are $\log _{10}$ probable number of bacilli/organ

the counting methods was statistically significant. However, in the chronic infection, the broth counts were higher than the plate counts. In the spleens, the mean broth count was $5.290 \log _{10} \mathrm{cfu} /$ organ and the plate count was $3.858 \log _{10} \mathrm{cfu} /$ spleen. The difference between these counts is $1.432 \log _{10}$ cfu / spleen (27-fold) so that, on the assumption that all bacilli that grew on plates also grew in broth, the bacilli capable of growing on plates comprised $3.7 \%(100 / 27)$ of the total count. In the lungs the mean broth count was $5.523 \log _{10}$ cfu /lungs, about 73 -fold higher than the plate count for the lungs. Thus the bacilli able to grow on plates comprised about 1.4\% (100/ 73 ) of the total. The differences between individual mice were significant $(\mathrm{p}=0.01)$ and highly significant between the counting methods $(\mathrm{p}<0.001)$.

In the remaining 9 mice no colonies were obtained on the neat dilution plates in either the lungs alone or in both lungs and spleen (Table 3). However, broth counts were obtainable from both organs in all 9 mice, though their mean values were appreciably lower than those in Table 1. Where a comparison could be made between counting methods in the spleens of the 7 mice with colonies in plate counts, the means of the broth counts $\left(4.347 \log _{10}\right.$ $\mathrm{cfu} / \mathrm{ml}$ ) were 19-fold higher than the corresponding plate counts (3.079 $\log _{10} \mathrm{cfu} / \mathrm{ml}$, giving $5.3 \%$ of the total), in approximate agreement with the 27 -fold (3.7\%) estimate of the difference between broth and plate counts obtained from Table 1.

The following changes occurred in the broth counts during incubation. The counts between the 3-week and the 6week readings increased on average in the lungs of each acute mice by 2.3 tubes and by 4.7 tubes in the spleens, and in each of the chronic mice by 2.0 tubes in lungs and 1.6 tubes in spleens. Thereafter, the increase from 6 weeks to 9 weeks was 1.5 tubes in the lungs of acute mice and 0.83 tubes in their spleens, while the increases in the lungs of chronic mice were 1.3 tubes and 1.0 tube in the spleens. Since an increase of 1 tube indicates a rise of about $\log _{10}$
0.8 , that is about $12 \%$, in the count, it is evident that counts increased during incubation, rapidly between 3 and 6 weeks and slowly between 6 and 9 weeks.

\section{Discussion}

The chronic infection experiment was unusual in that the intraperitoneal infection in vaccinated mice led to trapping of the bacilli in the peritoneal cavity, so that few bacilli reached the organs, and thus the plate counts were sometimes negative, with a count of less than $25 \mathrm{cfu} /$ organ. Variation, considerably greater than after intravenous or airborne infection, was also evident, the SD of the 4-week spleen counts, expressed as log10 cfu/organ, being 0.51 as compared to 0.23 for intravenous infection [5]. Evidence that growth in the broth cultures was M. tuberculosis was provided by the growth of typical colonies on 7H11 plates. That it was not due to sporadic contamination was shown by the usual complete absence of contamination in selective media, by a clear supernatant in the unshaken cultures and by the absence of any growth in the "no growth" zones of the broth cultures.

In log phase cultures ( $\mathrm{Hu} \mathrm{Y}-\mathrm{M}$, personal communication) and in the acute infection of mice, similar estimates of viable organisms were obtained in plate and broth counts However, our best estimate indicated that the bacilli in the chronic infections that would grow on plates was about $3.7 \%$ of the total population in spleens and $1.4 \%$ in lungs. This can be compared to the findings on a culture in $7 \mathrm{H} 9$ broth grown undisturbed for 100 days in the depths of liquid medium with caps screwed tightly on. In such a 100day culture, population A, capable of growth in broth but not on plates, was estimated by broth dilution counts to be $7.60 \log _{10}$ pnb / ml, while a smaller population $B$, that grew on plates, was estimated from parallel plate counts as $5.85 \log _{10} \mathrm{cfu} / \mathrm{ml}$.[1] Thus, population A was $1.75 \%$ of the total population. The corresponding estimates for a 30-day static culture were population $\mathrm{A}=9.983 \log 10 \mathrm{pnb}$ / $\mathrm{ml}$ and population $\mathrm{B}=8.013 \log 10 \mathrm{cfu} / \mathrm{ml}$, so that pop- 
Table 3: Plate and broth counts of $M$. tuberculosis in spleen and lungs of mice with chronic infections, when plate counts had no colonies

\begin{tabular}{|c|c|c|c|c|c|c|c|}
\hline \multirow{2}{*}{$\begin{array}{c}\text { Organ with no colonies in plate counts* } \\
\text { Spleen \& lungs }\end{array}$} & \multirow{2}{*}{$\begin{array}{c}\text { No. of mice } \\
2\end{array}$} & \multirow{2}{*}{$\begin{array}{l}\text { Organ } \\
\text { Spleen }\end{array}$} & \multirow{2}{*}{$\begin{array}{c}\text { Type of count }{ }^{\dagger} \\
\text { Broth }\end{array}$} & \multirow{2}{*}{$\begin{array}{c}\text { Mean count } \\
3.728\end{array}$} & \multirow{2}{*}{$\begin{array}{c}\text { SD } \\
0.708\end{array}$} & \multicolumn{2}{|c|}{$95 \%$ confidence limits } \\
\hline & & & & & & -2.638 & 10.094 \\
\hline & & Lungs & Broth & 4.247 & 1.428 & -8.580 & 17.073 \\
\hline \multirow[t]{3}{*}{ Lungs only } & 7 & Spleen & Plate & 3.079 & 0.960 & 2.192 & 3.968 \\
\hline & & & Broth & 4.347 & 0.823 & 3.586 & 5.108 \\
\hline & & Lungs & Broth & 4.202 & 0.624 & 3.625 & 4.778 \\
\hline
\end{tabular}

* A count of $<1.40 \log _{10}$ cfu/organ

† Plate counts are $\log _{10}$ cfu/organ: broth counts are $\log _{10}$ probable number of bacilli/organ

ulation B comprised $1.07 \%$ of the total population (Hu Y$\mathrm{M}$, personal communication).

These estimates suggest that the extent to which bacilli have gone into ill-defined dormancy might be measured as the proportion of a total bacterial population that can grow on plates. The lower this proportion, the greater the overall degree of "dormancy". Whatever, the theoretical significance of this simple technique for measuring dormancy, there is a practical implication for those undertaking long-term mouse experiments. Some end such an experiment with plate counts and others with culture in liquid medium. Those using only plate counts may be seriously underestimating the residual populations. It is also clear that there is much work to be done in seeing how various experimental conditions, such as the duration of the infection and the immune state of the mice, affect the ratio between broth and plate counts. Those exploring the development of new drugs need to know how these two populations respond to current anti-tuberculosis drugs and to novel drugs.

\section{Competing interests}

The author(s) declare that they have no competing interests.

\section{Authors contributions}

All three authors took part in the running of the experiments with JD contributing the most. DAM contributed the concept of parallel broth and plate counts.

\section{References}

I. Hu Y, Mangan JA, Dhillon J, Sole KM, Mitchison DA, Butcher PD, Coates ARM: Detection of mRNA Transcripts and active transcription in persistent Mycobacterium tuberculosis induced by exposure to rifampicin or pyrazinamide. J Bacteriol 2000, I 82:6358-6365.

2. Mitchison DA, Coates ARM: Predictive in vitro models of the sterilizing activity of anti-tuberculosis drugs. Current Pharmaceutical Design 2004, 10:3285-3295.

3. Voskuil MI, Schnappinger D, Visconti KC, Harrell MI, Dolganov GM, Sherman DR, Schoolnik GK: Inhibition of respiration by nitric oxide induces a Mycobacerium tuberculosis dormancy program. J Exp Med 2003, 198:705-713.
4. Mitchison DA, Allen BW, Carrol L, Dickinson JM, Aber VR: A selective oleic acid albumin agar medium for tubercle bacilli. J Med Microbiol 1972, 5: 165-175.

5. Dhillon J, Fielding R, Adler-Moore J, Goodall RL, Mitchison D: The activity of low-clearance liposomal amikacin in experimental murine tuberculosis. J Antimicrob Chemother 200I, 48:869-876.

6. Fisher RA, Yates F: Table VIII2. Densities of organisms estimated by the dilution method. In In Statistical tables for biological, agricultural and medical research Sixth edition. Edinburgh, Oliver and Boyd; 1963:66.

\section{Pre-publication history}

The pre-publication history for this paper can be accessed here:

http://www.biomedcentral.com/1471-2334/4/51/prepub

\begin{tabular}{|} 
Publish with Biomed Central and every \\
scientist can read your work free of charge \\
"BioMed Central will be the most significant development for \\
disseminating the results of biomedical research in our lifetime. " \\
Sir Paul Nurse, Cancer Research UK \\
Your research papers will be: \\
• available free of charge to the entire biomedical community \\
• peer reviewed and published immediately upon acceptance \\
• cited in PubMed and archived on PubMed Central \\
• yours - you keep the copyright \\
Submit your manuscript here: \\
http://www.biomedcentral.com/info/publishing_adv.asp
\end{tabular}

